\title{
The Naval Diving Safety Assessment Model Based on the Risk Matrix Theory
}

\author{
Hu Pei \\ Navy Submarine Academy \\ Qingdao, China \\ qdhupei@163.com
}

\author{
Hao Qian \\ Qingdao Campus of Navy Aeronautical University \\ Qingdao, China
}

\begin{abstract}
Our objective in this report is to analyze and assess safety risks in diving activities, and ensure fresh divers' safety underwater. We develop a diving training management safety assessment (DTMSA) model which is based on the safe risk matrix. Using corrected risk matrix formula in which combine quantitative risk rating value calculation model, and consider of managers' preference decision between the risk probability and the risk severity, and confirm the risk rating according to DTMSA standards. In actual training, it is a simple and effective safety risk control tool is which used to investigate problems in operation and management so as to sum up and deal with it in time. We suggest starting a further research in all diving process and unit, in order to establish a whole new diving safety risk assessment system for Navy.
\end{abstract}

Keywords-Diving; Safety; Assessment; Risk; Matrix

\section{INTRODUCTION}

For Navy diving training institutions, we have been using all kinds of safety risk assessment methods to manage and control various diving operations in recent years. Based on risk matrix, diving training management safety assessment (DTMSA) model is such a successful and satisfactory attempt.

The DTMSA is a comprehensive inspection program designed to assess the operational readiness and adherence to existing regulations, requirements, policies, and standards of Naval diving units and personnel. The major areas evaluated during an assessment include: administration, training, diving equipment and storage, divers compressor(s) and system components, support equipment, diving and rescue procedures. These assessments will be conducted by a DTMSA Team (DT) consisting of Naval Diving Safety Officer (NDSO) and/or Naval Diving Train Center (NDTC) representatives serving as DTMSA Inspectors (DI) and/or Diving Medical Officer (DMO).

DTMSA is a risk control tool which investigates problems at an operational and administrative level so they may be viewed and addressed. The criteria for selecting facilities to undergo compliance assessment must be attuned to the different levels and types of diving activity performed by a unit and address the controls needed to eliminate deficiencies at their root causes. The purpose of the DTMSA program is to preserve Naval Diving resources by identifying gaps in compliance with Safety and Occupational Health Regulations.

\section{RISK MATRIX THEORY}

\section{A. Risk Assessment}

Risk assessment is the determination of quantitative or qualitative estimate of risk related to a well-defined situation and a recognized threat (also called hazard). Quantitative risk assessment requires calculations of two components of risk $(\mathrm{R})$ : the potential consequences of an adverse event(c), and the probability (p) that the consequences will occur. An acceptable risk is a risk that is understood and tolerated usually because the cost or difficulty of implementing an effective countermeasure for the associated vulnerability exceeds the expectation of consequences[1].

Professor Du Duanfu believes that risk refers to the uncertainty of loss. It is the synthesis of multiple negative deviations caused by the uncertainty of the decisions and objective conditions of future actions, and be given the following mathematical formulas[4]:

$$
R=f(P, C)
$$

Equation (1):

$$
\begin{aligned}
& R \text {-risk; } \\
& P \text {-The probability of an adverse event; } \\
& C \text {-The consequences of an adverse event. }
\end{aligned}
$$

The definition of this risk proposed by Professor Du Duanfu has now been widely used.

When the income is difficult to quantify, or when compared with the loss, the benefit is negligible, the game of income and loss will be transformed into a game between various potential losses (The safety risk is this type of typical problem).So Equation (1) can continue to be simplified as a form of multiplication as a specific form of function:

$$
R=P \times C
$$




\section{B. Risk Matrix}

A Risk matrix is a matrix that is used during risk assessment to define the level of risk by considering the category of probability or likelihood against the category of consequence severity. This is a simple mechanism to increase visibility of risks and assist management decision making [2].

This method is put forward to buy Engineering Team in the United States Air Force Electronic Systems Center in April 1995. Since 1996, many projects are taken to evaluate project risk by risk matrix method [2].

Quantitative risk analysis depends on the impact of risk and risk probability of these two parameters. Measurement of risk affect the project once the risk degree is refers to the possible effect on the project caused by the size of the risk probability is the percentage; possibility of risk that is usually a subjective probability.

Equation (2) tells us, if we would get two key factors, one is the probability of an adverse event $(\mathrm{P})$, and another is the consequences of an adverse event $(C)$. In the risk matrix, we use another word "severity" to replace the factor word "consequences".

The probability of an diving accident occurring can be rated on a scale of A to E by DTMSA :

TABLE I. PROBABILITY RATING

\begin{tabular}{|c|c|c|}
\hline Label & Probability & Introduction \\
\hline A & Unlikely & Can assume will rarely occur in career/equipment \\
life.
\end{tabular}

The severity of an accident can be rated in a similar way:

TABLE II. SEVERITY RATING

\begin{tabular}{|c|c|c|}
\hline Label & Severity & Introduction \\
\hline I & Negligible & $\begin{array}{c}\text { Minimal mission degradation, injury, occupational } \\
\text { illness, or negligible system damage. }\end{array}$ \\
\hline II & Minor & $\begin{array}{c}\text { Trivial mission degradation, injury, occupational } \\
\text { illness, or minor system damage. }\end{array}$ \\
\hline III & Major & $\begin{array}{c}\text { Key mission degradation, injury, minor } \\
\text { occupational illness, or major system damage. }\end{array}$ \\
\hline IV & Critical & $\begin{array}{c}\text { Chief mission degradation, severe injury, } \\
\text { occupational illness, or critical system damage. }\end{array}$ \\
\hline V & Catastrophic & $\begin{array}{c}\text { Complete mission failure, death, or loss of a diver's } \\
\text { air system. }\end{array}$ \\
\hline
\end{tabular}

\section{NAVAL DIVING SAFETY ASSESSMENT}

\section{A. DTMSA Risk Rating Code}

DUSA findings have the potential to affect the health and safety of the individual diver and the safety of the facility or equipment used by divers to conduct operations. By utilizing a 'probability/severity' Risk Assessment Code (RAC) matrix, a RAC value is assigned to each finding. The final rating of the unit's inspection is based on the lowest
RAC assigned which may affect the unit's authorization to dive. Finding Ratings are described below:

- RAC 1 - Unit is suspended from conducting diving operations until reauthorized by the NDSO. Indicates substantial probability that death or serious physical harm could result, and management knew or should have known of the hazard.

- RAC 2 - A temporary suspension is issued until all Corrective Actions (CA) are completed, prior to the authorization to continue diving operations is granted by the Line Office Diving Officer (LODO).Indicates moderate probability injury or illness.

- $\mathrm{RAC} 3$ - It is required that CA are completed and confirmed by LODO within 30 days of the issued CA Plan. Indicates that equipment or divers must be removed from operations due to lack of appropriate maintenance or authorization.

- RAC 4-Complete CA Plan confirmed by LODO.S

- RAC 5 - Complete CA Plan confirmed by LODO. Majority of areas evaluated meets the minimum requirements.

\section{B. Risk Rating}

On the basis of the probability and severity ratings, a risk rating matrix can be constructed to give DTMSA Risk Rating Code.

TABLE III. RISK RATING

\begin{tabular}{|c|c|c|c|c|c|}
\hline \multirow{2}{*}{ Probability } & \multicolumn{5}{|c|}{ Severity } \\
\cline { 2 - 6 } & $I$ & $I I$ & $I I$ & $I V$ & $V$ \\
\hline $\boldsymbol{A}$ & 1 & 1 & 1 & 2 & 2 \\
\hline $\boldsymbol{B}$ & 1 & 1 & 2 & 3 & 3 \\
\hline $\boldsymbol{C}$ & 1 & 2 & 3 & 4 & 4 \\
\hline $\boldsymbol{D}$ & 2 & 3 & 4 & 5 & 5 \\
\hline $\boldsymbol{E}$ & 2 & 3 & 4 & 5 & 5 \\
\hline
\end{tabular}

\section{Problem}

However, there is a problem in the above method. That is, it is impossible to distinguish contribution between the risk probability and the severity impact on the risk rating.

For some diving action, according to its characteristics, it believes that the risk of a great loss is high, regardless of the probability of its occurrence. There are also some actions, the risk is higher than a certain probability value, no matter how big its impact.

This shows that the risk rating is determined by the risk probability and the risk severity, but people have different preferences for two factors. We should assign different weights to $\mathrm{P}$ and $\mathrm{C}$ to classify risk level, and more accurately determine the risk importance rating of this factor. 


\section{Risk Rating method Improvement}

We use a new risk rating classification formula based on the equation (2) :

$$
R=P_{f}^{\alpha} \times C_{f}^{\beta}
$$

With definition, $P_{f}$ is the assignment of risk probability $P ; C_{f}$ is the assignment of risk severity $C . \alpha$ is the weight factor of risk probability; $\beta$ is the weight factor of risk severity, and $\alpha+\beta=1$.

We divide the values of $\alpha$ and $\beta$ into 9 groups, and accurate to 0.1 , so we can get these values:

$$
\begin{array}{lll}
\alpha=0.1, \beta=0.9 ; & \alpha=0.2, \beta=0.8 ; & \alpha=0.3, \beta=0.7 ; \\
\alpha=0.4, \beta=0.6 ; & \alpha=0.5, \beta=0.5 ; & \alpha=0.6, \beta=0.4 ; \\
\alpha=0.7, \beta=0.3 ; & \alpha=0.8, \beta=0.2 ; & \alpha=0.9, \beta=0.1 .
\end{array}
$$

In this paper, the $P_{f}$ value interval is $[10,60]$, and the $C_{f}$ value interval is $[10,60]$. So, risk rating $R$ value interval is also $[10,60]$.These specific values are as follows[7][8]:

TABLE IV. Probability VAlue

\begin{tabular}{|c|c|c|c|}
\hline Lable & Probability & Range & Value \\
\hline A & Unlikely & $0-10 \%$ & {$[10,15)$} \\
\hline B & Seldom & $11 \%-40 \%$ & {$[15,30)$} \\
\hline C & Occasional & $41 \%-60 \%$ & {$[30,40)$} \\
\hline D & Likely & $61 \%-90 \%$ & {$[40,55)$} \\
\hline E & Frequent & $91 \%-100 \%$ & {$[55,60]$} \\
\hline
\end{tabular}

TABLE V. SEVERITY VALUE

\begin{tabular}{|c|c|c|c|c|}
\hline Negligible & Minor & Major & Critical & Catastrophic \\
\hline$[10,20)$ & {$[20,30)$} & {$[30,40)$} & {$[40,50)$} & {$[50,60]$} \\
\hline
\end{tabular}

TABLE VI. RISK RATING VALUE

\begin{tabular}{|c|c|c|c|c|}
\hline Lowest & Lower & Medium & Higher & Highest \\
\hline$[10,20)$ & {$[20,30)$} & {$[30,40)$} & {$[40,50)$} & {$[50,60]$} \\
\hline
\end{tabular}

\section{ACTUAL PRACTICAL}

According to the DTSAM project need, we picked up some diving and underwater warfare experts to prepare the expert committee. In order to avoid the error assessment, the numbers of experts are more than 10 people. Experts need in-depth research and analysis from various aspects of diving training, combined with their own experience and theoretical knowledge to identify risk indicators, and to evaluate the index.
We also collect a large number of diving accidents data to improve the risk matrix model[6].So, from these data, the DTSAM expert committee analyzed the risk factors which affect the diving safety, and determined the risk index is .These risk indicators can be applied to the risk matrix to indicate the risk level of an action.

TABLE VII. RISK RATING IN ACTUAL DIVING TRAIN

\begin{tabular}{|c|c|c|c|c|}
\hline NO. & Risk & Probability & Severity & $\begin{array}{c}\text { Risk } \\
\text { Rating }\end{array}$ \\
\hline $\mathbf{1}$ & General & B & I & 2 \\
\hline $\mathbf{2}$ & Lost diver & A & $V$ & 2 \\
\hline $\mathbf{3}$ & Unconscious diver & B & $V$ & 3 \\
\hline $\mathbf{4}$ & AGE & D & II & 3 \\
\hline $\mathbf{5}$ & DCS & C & IV & 4 \\
\hline $\mathbf{6}$ & $\begin{array}{c}\text { Rig } \\
\text { Malfunction }\end{array}$ & D & III & 4 \\
\hline $\mathbf{7}$ & Mechanical Injury & E & II & 3 \\
\hline $\mathbf{8}$ & Loss of Comms & D & III & 4 \\
\hline $\mathbf{9}$ & $\begin{array}{c}\text { Small boat } \\
\text { malfunction }\end{array}$ & C & II & 2 \\
\hline
\end{tabular}

We use the equation (3) to correct our risk rating.

- Risk one: we choice $P_{f}=20$, $C_{f}=15, \alpha=0.9, \beta=0.1$ (It means probability influence greater in risk rating, and severity could be ignored ).

So, we get:

$$
R=P_{f}^{0.9} \times C_{f}^{0.1}=20^{0.9} \times 15^{0.1}=19.433 .
$$

- Risk two: we choice $P_{f}=13$, $C_{f}=55, \alpha=0.2, \beta=0.8$ (It means severity influence greater, and probability could be smaller).

So, we get :

$$
R=P_{f}^{0.2} \times C_{f}^{0.8}=13^{0.2} \times 55^{0.8}=41.217 .
$$

- Risk three: we choice $P_{f}=22$, $C_{f}=55, \alpha=0.3, \beta=0.7$.

So, we get: $R=41.781$.

- Risk four: we choice $P_{f}=50$, $C_{f}=25, \alpha=0.6, \beta=0.4$.

So, we get: $R=37.893$.

- Risk five: we choice $P_{f}=38$, $C_{f}=45, \alpha=0.4, \beta=0.6$.

So, we get: $R=42.057$. 
- Risk six: we choice $P_{f}=48$, $C_{f}=35, \alpha=0.5, \beta=0.5$.

So, we get: $R=40.988$.

- Risk seven: we choice $P_{f}=59$, $C_{f}=25, \alpha=0.7, \beta=0.3$.

So, we get: $R=45.601$.

- Risk eight: we choice $P_{f}=52$, $C_{f}=35, \alpha=0.8, \beta=0.2$.

So, we get: $R=48.041$.

- Risk nine: we choice $P_{f}=35$, $C_{f}=25, \alpha=0.7, \beta=0.3$.

So, we get: $R=31.640$.

We correct the risk rating like follow table:

TABLE VIII. CORRECTED RISK RATING

\begin{tabular}{|c|c|c|c|c|c|c|c|c|c|}
\hline \multirow{2}{*}{ Risk } & \multicolumn{3}{|c|}{ Probability } & \multicolumn{2}{|c|}{ Severity } & \multicolumn{2}{c|}{ Factor } & \multicolumn{2}{c|}{$\begin{array}{c}\text { Risk } \\
\text { Rating }\end{array}$} \\
\cline { 6 - 9 } General & B & $\begin{array}{c}11 \%- \\
40 \%\end{array}$ & 20 & I & 15 & 0.9 & 0.1 & $\begin{array}{c}19.4 \\
33\end{array}$ & 2 \\
\hline Lost diver & A & $0-10 \%$ & 13 & $V$ & 55 & 0.2 & 0.8 & $\begin{array}{c}41.2 \\
17\end{array}$ & 4 \\
\hline $\begin{array}{c}\text { Unconscious } \\
\text { diver }\end{array}$ & B & $\begin{array}{c}11 \%- \\
40 \%\end{array}$ & 22 & V & 55 & 0.3 & 0.7 & $\begin{array}{c}41.7 \\
81\end{array}$ & 4 \\
\hline AGE & D & $\begin{array}{c}61 \%- \\
90 \%\end{array}$ & 50 & II & 25 & 0.6 & 0.4 & $\begin{array}{c}37.8 \\
93\end{array}$ & 3 \\
\hline DCS & C & $\begin{array}{c}41 \%- \\
60 \%\end{array}$ & 38 & IV & 45 & 0.4 & 0.6 & $\begin{array}{c}42.0 \\
57\end{array}$ & 4 \\
\hline $\begin{array}{c}\text { Rig } \\
\text { Malfunction }\end{array}$ & D & $\begin{array}{c}61 \%- \\
90 \%\end{array}$ & 48 & III & 35 & 0.5 & 0.5 & $\begin{array}{c}40.9 \\
88\end{array}$ & 4 \\
\hline $\begin{array}{c}\text { Mechanic-al } \\
\text { Injury }\end{array}$ & E & $\begin{array}{c}91 \%- \\
100 \%\end{array}$ & 59 & II & 25 & 0.7 & 0.3 & $\begin{array}{c}45.6 \\
01\end{array}$ & 4 \\
\hline $\begin{array}{c}\text { Loss of } \\
\text { Comms }\end{array}$ & D & $\begin{array}{c}61 \%- \\
90 \%\end{array}$ & 52 & III & 35 & 0.8 & 0.2 & $\begin{array}{c}48.0 \\
41\end{array}$ & 4 \\
\hline $\begin{array}{c}\text { Small boat } \\
\text { malfunction }\end{array}$ & C & $\begin{array}{c}41 \%- \\
60 \%\end{array}$ & 35 & II & 25 & 0.7 & 0.3 & $\begin{array}{c}31.6 \\
40\end{array}$ & 3 \\
\hline
\end{tabular}

From the above table, We can clearly find that the risk rating is different in the NO 2,3,7 and 9 .These corrected risk rating level are promote, and are conforming better than old ones in the actual diving safety assessment.

\section{CONCLUSION}

Through the actual example, we use different weights about the risk severity and the risk probability criteria, and lead the risk classification and importance into change. The new results come forth from diving unit officers' decision aggregation. According to specific requirements of the risk module, diving unit officers decide to give more attention to which criteria is. These choices make the result more actual and appropriate.

In short, the equation (3), the new model proposed in this paper, its advantage is which can combine quantitative risk rating value calculation model, and consider of managers' preference decision between the risk probability and the risk severity. But it also has some disadvantages: risk probability and risk impact weight assignments are very important, and these assignments are given by experts. The weight assignment accuracy may be influence by experts' subjective idea. So, it needs to improve the requirements and methods in experts selected.

\section{REFERENCES}

[1] Engert P A, and Lansdowne Z F, "Risk matrix user's guide[R],"Bed ford:The MITRE Corporation, 1999:18 - 39.

[2] Talbot, Julian. "What's right with risk matrices?". Jakeman Business Solutions

[3] He Zhi"Risk Management for overseas construction projects," International Journal of Project Management[J].1995,13,231-237(In Chinese).

[4] Du Duanfu, "integrated integration method in risk management of major engineering projects[J],"China's management science.1996(12):24-38(In Chinese).

[5] Zhang Meng, and Lin Benhai, "Subway construction project risk assessment method and its application[J],"'Inspection and cost of construction supervision. 2012, 5 (2)(In Chinese).

[6] Paul D. Thompson,"The Cardiovascular Risks of Diving," Recreationa Diving Fatalities Workshop Proceedings, April 8-10, 2010.

[7] Fu Sha, "The application of an improved risk matrix method in the risk assessment of network system," Computer System Application[J],2012,21(1):148-167(In Chinese).

[8] Sun Ken, Cai Hongtao, Yang Chonghao, "The construction method of risk matrix in risk quantitative analysis," Journal of North China Water Conservancy and hydroelectric Institute, 2011,32(5):158-160(In Chinese). 